\title{
Why is heptagonal symmetry so rare in art and architecture?
}

\author{
Arie van der Lee \\ Institut Européen des Membranes, Université de Montpellier, ENSCM, CNRS, Montpellier, France \\ arie.van-der-lee@umontpellier.fr
}

Seven and fivefold point symmetries are incompatible with three-dimensional translation symmetry and thus very rare as symmetry elements of building blocks in tilings and pavings. Heptagonal symmetry elements as local symmetry elements in isolated objects in art, architecture and nature appear surprisingly much less frequently than pentagonally shaped designs. This presentation aims to give some objective, but also subjective reasons why architects, designers and artists rarely choose for local heptagonal symmetry in their creations. It is argued that reasons that are commonly put forward as explanation for the choice for heptagonal symmetry are too simplistic and probably not true. A number of examples is presented where the designer has chosen for heptagonal symmetry as a key element for creation and reasons for these choices are proposed where possible. Special emphasis will be given to two outstanding heptagonal religious edifices in French Occitany and larger heptagonal urban geometries in the low countries.

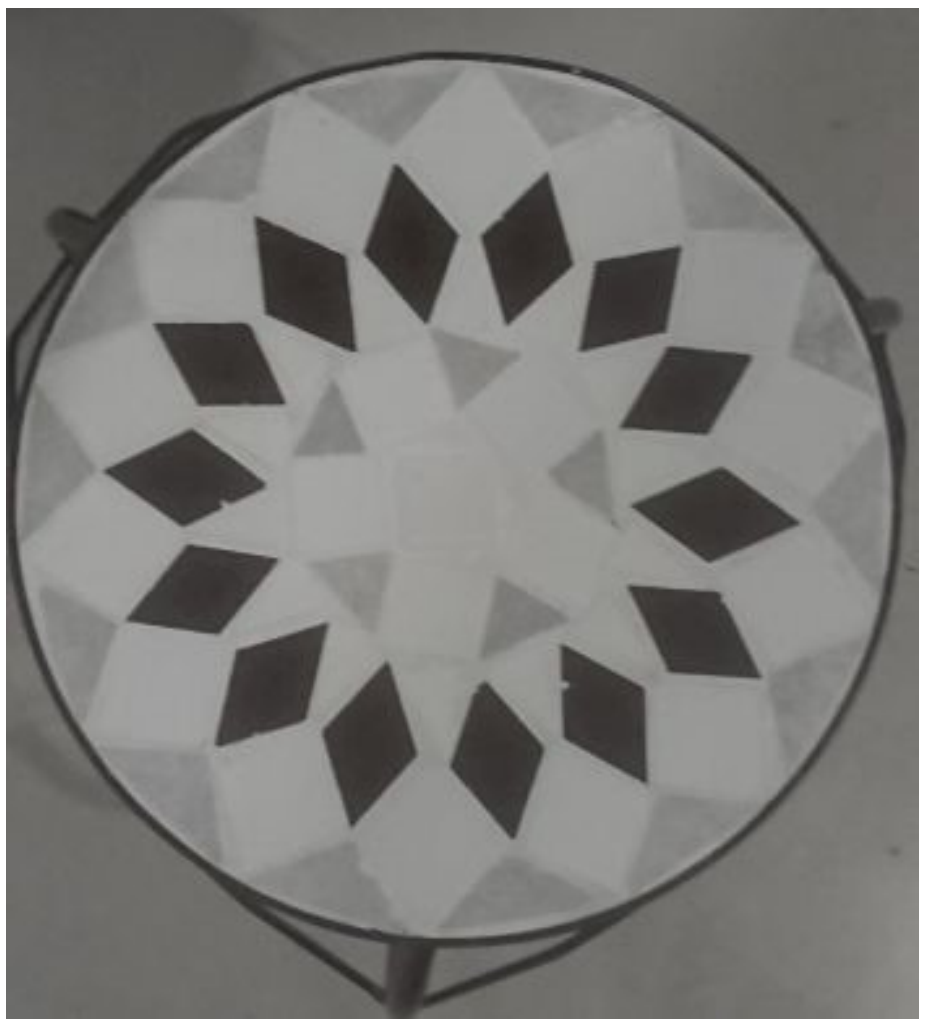

Figure 1. Tettareskaidekagonal and heptagonal creative design for a stool in the changing booth of a clothes store in Lyon, France

\section{Keywords: heptagonal symmetry; art; architecture; design}

